\title{
Full-scale operation of a novel two-pipe active beam system for simultaneous heating and cooling of office buildings
}

\author{
Alessandro Maccarini ${ }^{1, *}$, Göran Hultmark ${ }^{2}$, Niels C. Bergsøe ${ }^{1}$, and Alireza Afshari ${ }^{1}$ \\ ${ }^{1}$ Danish Building Research Institute, Aalborg University Copenhagen, A.C. Meyers Vænge 15, 2450 Copenhagen, Denmark \\ ${ }^{2}$ Lindab ICS, Lucernemarken 17, 3520 Farum, Denmark
}

\begin{abstract}
This paper presents an investigation on the operation of a novel active beam system installed in an office building located in Jönköping, Sweden. The system consists of two parts: a dedicated outdoor air system (DOAS) to satisfy latent loads and ventilation requirements, and a water circuit to meet sensible heating and cooling loads. The novelty of the system is in relation to the water circuit, which is able to provide simultaneous heating and cooling through a single water loop that is near the room temperature. The energy performance of the system is currently being monitored through a number of sensors placed along the water circuit. Relevant physical parameters are being measured and data are available through a monitoring system. A preliminary analysis shows that the system is performing as designed. Results are shown for a typical week in winter, spring and summer. In particular, the supply water temperature in the circuit was between $20^{\circ} \mathrm{C}$ (in summer) and $23.2^{\circ} \mathrm{C}$ (in winter). The maximum supply/return temperature difference was found in summer and it assumed a value of $1.5 \mathrm{~K}$. It is noticed that in spring supply and return water temperatures almost overlap.
\end{abstract}

\section{Introduction}

Active beam systems have gained increased recognition over the last decades as a sustainable technology able to provide good thermal comfort and advantages in terms of energy savings [1-2]. Although they are often referred to as "chilled" beams, in many cases active beams can be used for both heating and cooling [3].

Figure 1 shows the sectional view of a typical active beam unit. The water is circulated in a heat exchanger placed inside the active beam. The primary air enters the room via a pressure plenum. The high air velocity generated by nozzles reduces the static pressure and induces room air that passes the heat exchanger before it mixes with the primary air. The mixed air is discharged into the room through slots along both sides of the beam [4-5].

Conventional active beam systems consist of two main parts: a dedicated outdoor air system (DOAS) to satisfy latent loads and ventilation requirements, and a water circuit to meet sensible heating and cooling loads, as shown in Fig. 2. The water circuit is typically available in a four-pipe configuration, which allows simultaneous delivery of heating and cooling using two separated loops [6].

Recent studies conducted by the authors have investigated the possibility to design a novel active beam system able to provide simultaneous heating and cooling using only a single water loop (Fig. 2) [7-8]. The main characteristic of this novel system is related to the supply water temperature, which is around $22^{\circ} \mathrm{C}$ all year round.
Therefore, a room with an indoor air temperature of $20^{\circ} \mathrm{C}$ would be heated, while a room at $24^{\circ} \mathrm{C}$ would be cooled. Return water flows from single zones are mixed and the common return water flow is delivered to the central plant, which will operate in either heating or cooling mode, depending on the average resulting thermal loads in the building.

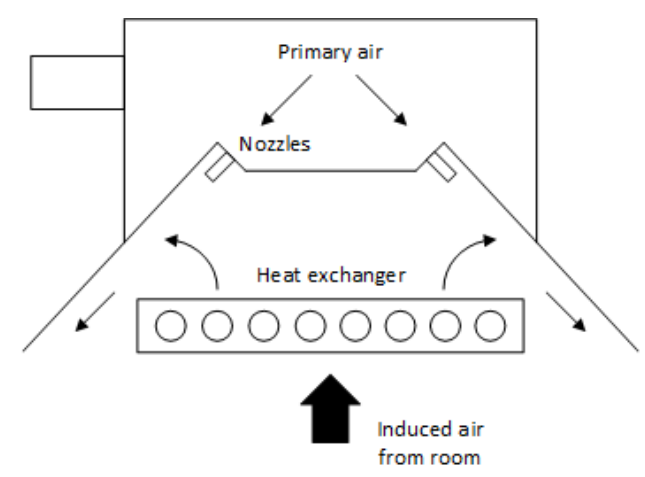

Fig. 1. Sectional view of a typical active beam unit

Beside the advantages in terms of exploitation of sustainable energy sources (due to water temperatures near ambient temperature), this piping configuration opens opportunities for transferring heat among building zones when simultaneous heating and cooling occurs in a building. By mixing the return pipes from individual zones, excess heat can be transferred from warm to cold zones through the water circuit.

\footnotetext{
* Corresponding author: alm@sbi.aau.dk
} 

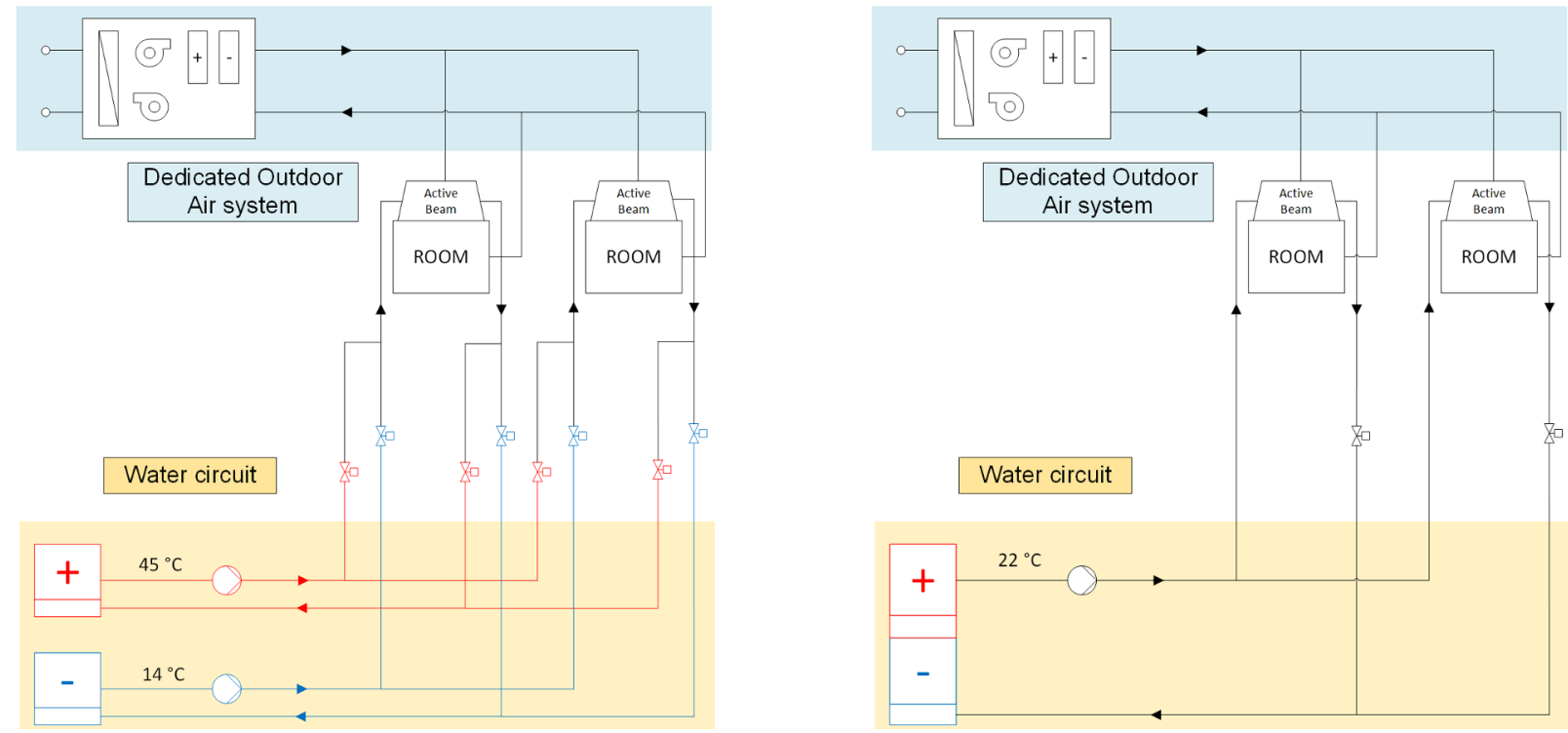

Fig. 2. Conventional four-pipe active beam system (left) vs. Novel two-pipe active beam system (right)

As shown by previous simulation-based works, this behaviour leads to a reduction of the annual energy use by approximately $18 \%$ when comparing the innovative twopipe system with a traditional four-pipe system [9]. The design of the two-pipe systems also allows to save installation cost due to the need of only one water circulation pump, fewer pipes and no control valves. On the other hand, due to lower temperature differences between room air and water in the active beam, the two-pipe system requires approximately four times more heat transfer area than conventional four-pipe active beam systems. In addition, the design of the two-pipe system does not allow individual control of the air temperature in rooms.

So far, the energy performance of the novel two-pipe system have been evaluated through modelling and simulations studies. In this paper, preliminary data regarding the operation of the first full-scale two-pipe active beam system are presented. Measurements of indoor air temperature in one floor of the building are also shown in this paper in order to provide an indication of the thermal conditions provided by the system.

\section{Methodology}

The "Runda Huset" is a sixteen-storey office building constructed in 2015 and located in Jonkoping, Sweden (Fig.3). In author's knowledge, this is the first building equipped with the novel two-pipe active beam system described. Fourteen floors of the building are dedicated to offices, the ground floor hosts a restaurant and the top floor accommodates conference rooms.

\subsection{Design and sizing of the system}

The two-pipe system was designed in order to maintain an indoor air temperature of $21^{\circ} \mathrm{C}$ in winter and $23^{\circ} \mathrm{C}$ in summer. As previously mentioned, the system consists of two parts: a DOAS and a water circuit.
The DOAS serves the fourteen floors dedicated to offices and it consists of supply and return fans, heating and cooling coils, and a heat recovery unit. It mostly operates as a CAV system, delivering a constant air mass flow rate of $0.03 \mathrm{~kg} / \mathrm{s}$ to each beam with a constant supply temperature of $21^{\circ} \mathrm{C}$. Only few spaces are equipped with local VAV units in order to boost the cooling capacity when required (e.g. meeting rooms). Ground and top floor are equipped with decentralized air units due to different ventilation requirements.

The water circuit was designed to operate with a constant water mass flow rate $(0.04 \mathrm{~kg} / \mathrm{s}$ per beam $)$, and a variable supply water temperature according to outdoor air temperature. In particular, at extreme low outdoor air temperatures, a maximum supply water temperature of $23^{\circ} \mathrm{C}$ was set. At extreme high outdoor air temperatures, a minimum supply water temperature of $20^{\circ} \mathrm{C}$ was set. A linear correlation was used between the two extreme points, as illustrated in Fig. 4.

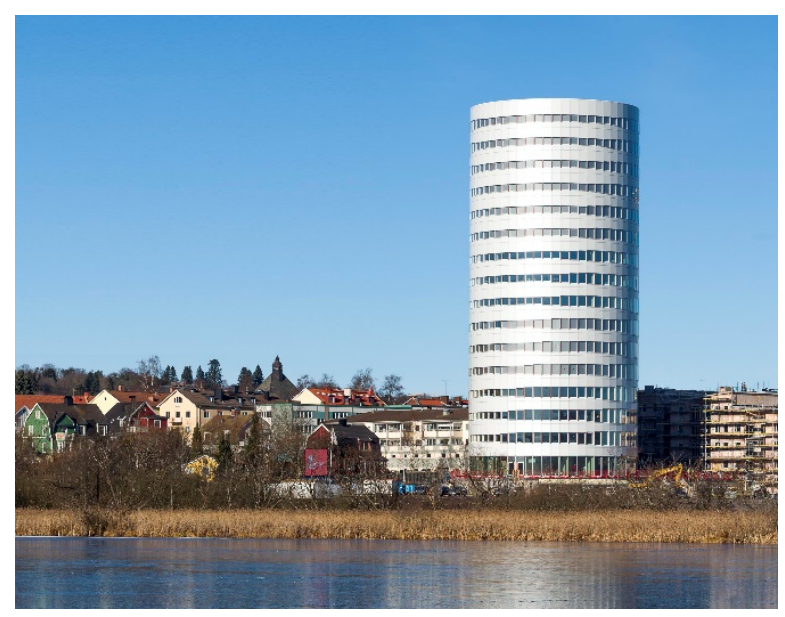

Fig. 3. Runda Huset building in Jönköping (Sweden) 
It is worth highlighting that no feedback controllers are installed in the building. Therefore, the system is solely regulated according to outdoor air temperature. Comfortable thermal conditions in the building are achieved thanks to the so-called self-regulating effect. Since the water circuit operates at temperatures close to room temperature the rate of heat transfer is very sensitive to changes in room temperature [9].

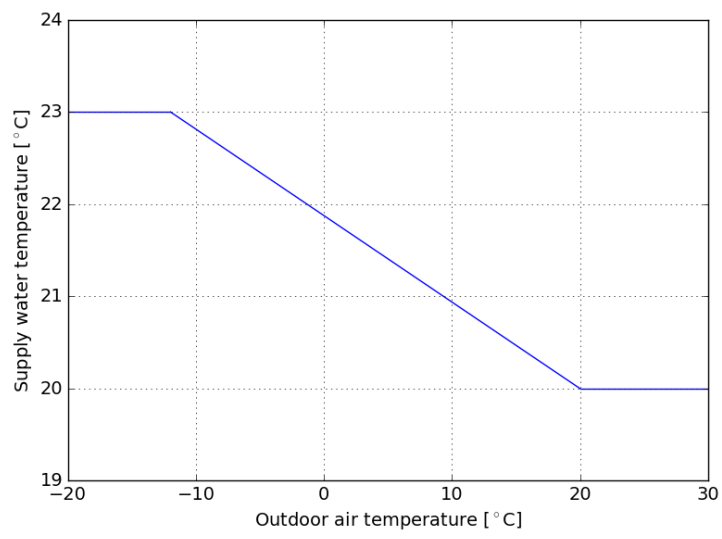

Fig. 4. Regulation of supply water temperature

In terms of sizing, 550 active beam units named SOLUS [10] were installed in the building. Each unit has a capacity of approximately $400 \mathrm{~W}$ and $700 \mathrm{~W}$ respectively in heating and cooling mode, according to the design values of temperatures and mass flow rates previously mentioned.

\subsection{Monitoring system}

The monitoring system was installed in order to collect relevant parameters of the operation of the two-pipe system. In particular, this paper focuses on presenting preliminary data regarding the water circuit, whose configuration represents the novelty of the system. The water circuit is illustrated in details in Fig. 5. Heating is provided by the local district heating system, while cooling by a nearby lake.

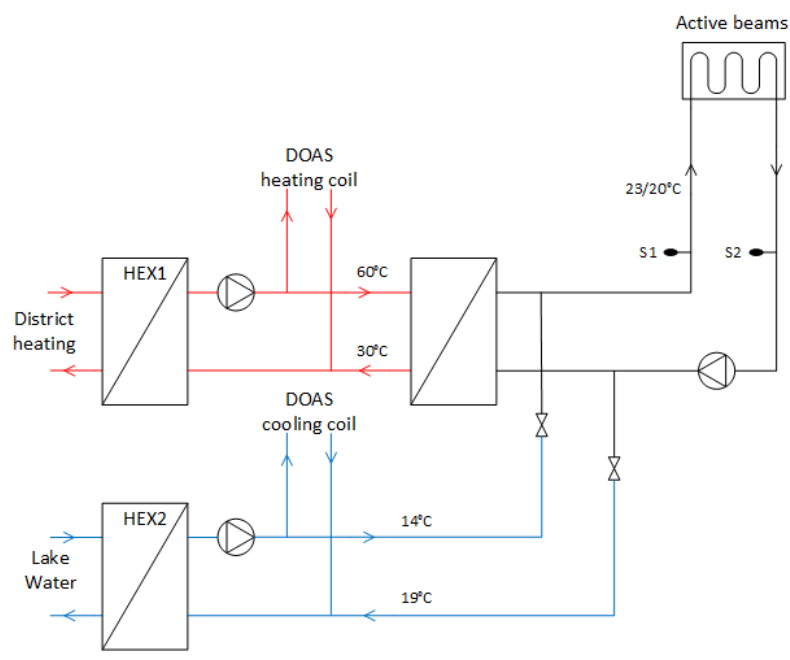

Fig. 5. Scheme of the water circuit including sensors
The heat exchanger HEX1 connects the district heating network to an intermediate hot water circuit with temperatures of $60-30^{\circ} \mathrm{C}$.

This circuit serves both the DOAS unit (heating coils) and the active beams water circuit. HEX2 connects the lake water network to an intermediate chilled water circuit with temperature of $14-19^{\circ} \mathrm{C}$. This circuit serves both the DOAS unit (cooling coils) and the active beams water circuit. Two temperature sensors (accuracy $\pm 0.2^{\circ} \mathrm{C}$ ) were placed in the circuit in order to monitor the supply (S1) and return (S2) water temperature.

\subsection{Indoor air temperature measurements}

In order to provide an indication of the thermal conditions provided by the two-pipe system, measurements of indoor air temperature were carried out by the authors in one floor of the building, which was chosen according to access permissions given by the building owner.

The floor accommodates a large open office space (approximately $200 \mathrm{~m}^{2}$ ), few single office rooms, and a meeting room. Two air temperature sensors (accuracy $\pm 0.3^{\circ} \mathrm{C}$ ) were placed in two different locations of the open office space, as illustrated in Fig. 6. The sensors were placed at $1.1 \mathrm{~m}$ height. Measurements were collected for a continuous period of 24 hours using $5 \mathrm{~min}$ timeaveraged values for a typical winter day ( $3^{\text {rd }}$ of March $2017)$, and a typical summer day (24 $4^{\text {th }}$ of August 2017).

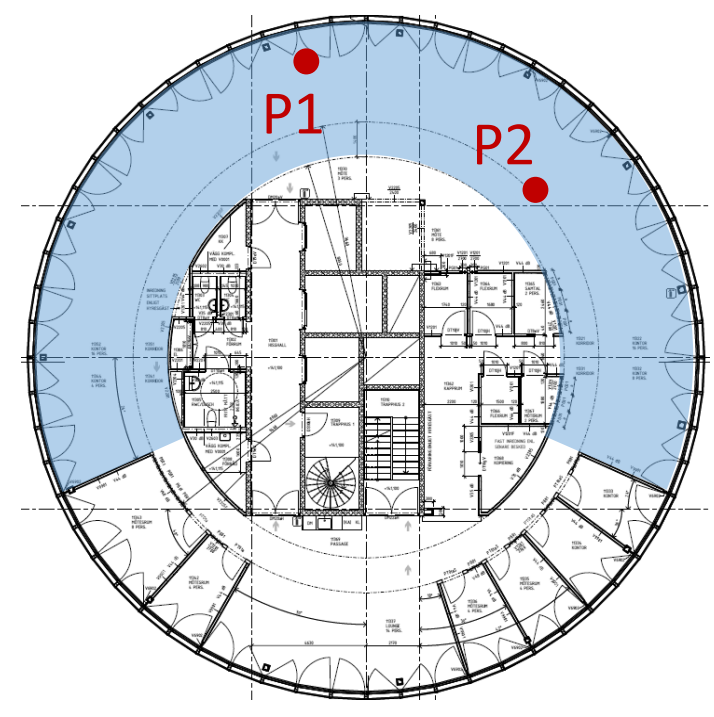

Fig. 6. Floor plan of the 13th floor of the building. P1 and P2 are the two locations where measurements were performed. The blue area represents the large open office space

\section{Results and discussion}

Results in terms of supply and return water temperatures, thermal power and energy use of the active beam circuit are shown for three typical weeks: winter, spring and summer. In addition, indoor air temperatures in one floor of the building are shown for a typical winter day and a typical summer day. 


\subsection{Supply and return water temperatures}

Fig. 7 shows the hourly values of supply and return water temperatures in the active beam circuit for a typical winter week (from the $29^{\text {th }}$ of January to the $4^{\text {th }}$ of February 2018). The graph also shows the outdoor air temperature.

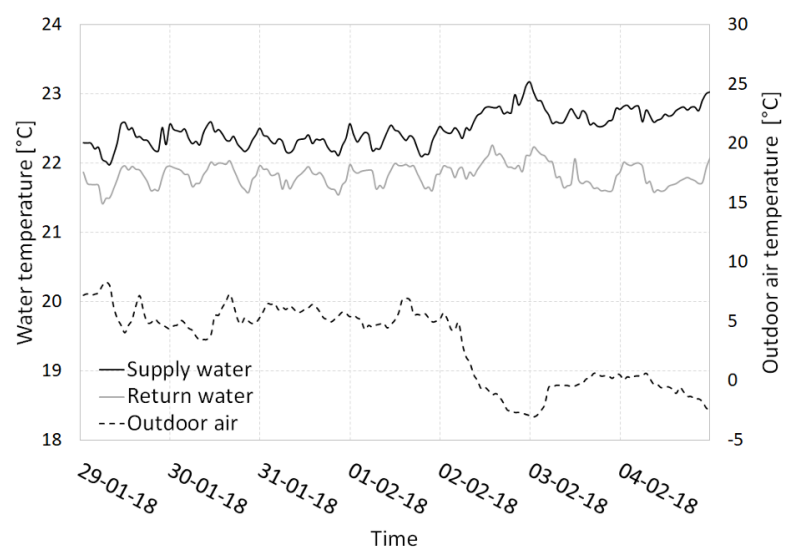

Fig. 7. Winter : supply and return water temperatures

The maximum supply water temperature is $23.2^{\circ} \mathrm{C}$ and, as expected, it occurs in correspondence of the minimum outdoor air temperature. The minimum supply water temperature occurs in correspondence of the maximum outdoor air temperature and it assumes a value of $22^{\circ} \mathrm{C}$. The maximum temperature difference between supply and return water is approximately $1.2 \mathrm{~K}$ and it is found in correspondence of the minimum outdoor air temperature. This is because, in case of low outdoor air temperatures, the building requires larger heating demand. Since the system operates with constant water mass flow rate, this results in larger supply/return temperature differences. It is also noticed that the supply water temperature is always higher than the return water temperature, meaning that the building is always in heating demand mode.

Fig. 8 shows the hourly values of supply and return water temperatures for a typical spring week (from the $9^{\text {th }}$ of April to the $15^{\text {th }}$ of April 2018). The maximum supply water temperature is approximately $22.5^{\circ} \mathrm{C}$ while the minimum supply water temperature is approximately $21.5^{\circ} \mathrm{C}$. It is noticed that supply and return water temperatures overlap for most of the time (during daytime), leading to small supply/return temperature differences. This means that heating and cooling loads in the building are balancing each other, and the system is providing simultaneous heating and cooling. At nights, higher supply/return water temperature differences are obtained, meaning that the building is in heating demand mode. The graph also shows how the supply water temperature oscillates according to the outdoor air temperature. During the day, when outdoor air temperatures are higher, the supply water temperature is lower. The opposite behaviour occurs during nights.

Fig. 9 shows the hourly values of supply and return water temperatures for a typical summer week (from the $30^{\text {th }}$ of July to the $5^{\text {th }}$ of August 2018).

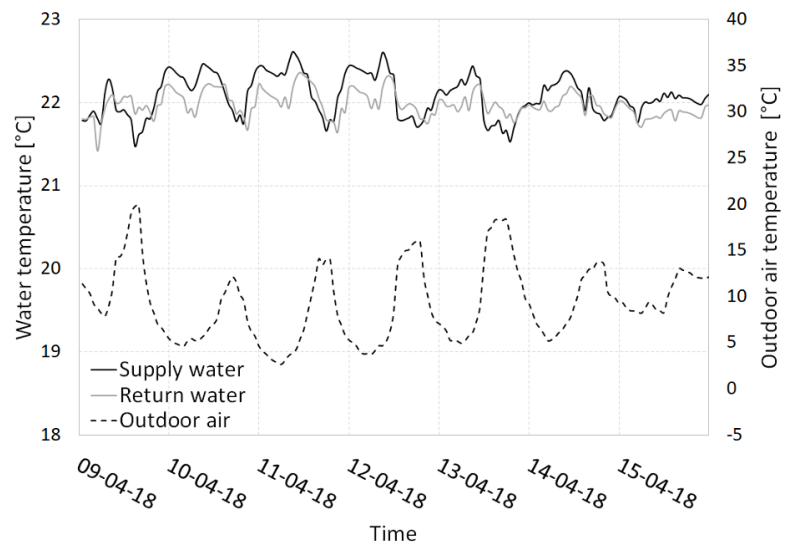

Fig. 8. Spring : supply and return water temperatures

The maximum and minimum supply water temperatures are $21.5^{\circ} \mathrm{C}$ and $20^{\circ} \mathrm{C}$, respectively. In this case, the overlapping between supply and return water temperature occurs during nights, when the building is unoccupied. During daytime, the supply water temperature is always lower than the return water temperature, meaning that the system is providing cooling energy to the zones. The maximum temperature difference between supply and return water is $1.5 \mathrm{~K}$.

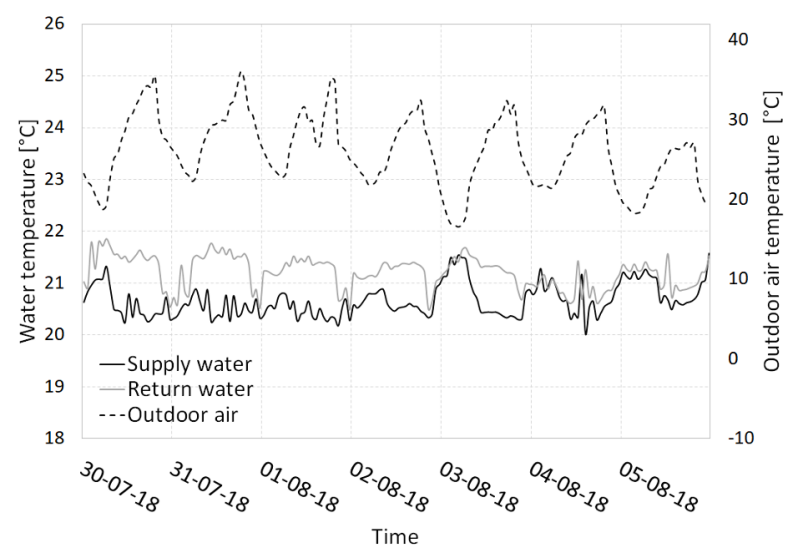

Fig. 9. Summer : suppy and return water temperatures

\subsection{Thermal power and energy use}

Figs. 10-11-12 show the thermal power delivered by the water system for the three typical weeks. The thermal power delivered is calculated as:

$$
\dot{Q}=\dot{m} c_{p}\left(T_{\text {sup }}-T_{\text {ret }}\right)
$$

Where $\dot{m}$ is the constant water mass flow rate (equal to approximately $22 \mathrm{~kg} / \mathrm{s}$ ), $c_{p}$ is the water heat capacity, $T_{\text {sup }}$ is the actual supply water temperature and $T_{r e t}$ is the actual return water temperature.

The peak heating power occurs during the winter week and it assumes a value of approximately $110 \mathrm{~kW}$, while the cooling peak load occurs in summer and it assumes a value of approximately -145 . In spring, the system oscillates between heating mode at night (positive thermal power) and cooling mode at day (negative thermal power). 
Fig. 13 shows the energy use for the three typical weeks provided by the water system. This was calculated by integrating the thermal power profiles depicted in Fig. 1011-12. The maximum energy use is found for the winter week and it assumes a value of $1.2 \mathrm{kWh} / \mathrm{m}^{2}$. The minimum energy use is obtained for the spring week and it assumes a value of approximately $0.4 \mathrm{kWh} / \mathrm{m}^{2}$.

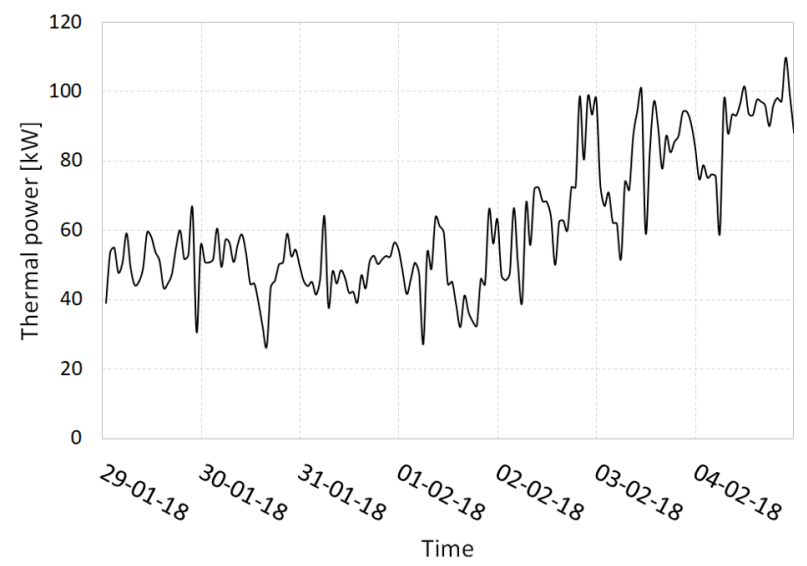

Fig. 10. Thermal power profile during winter week

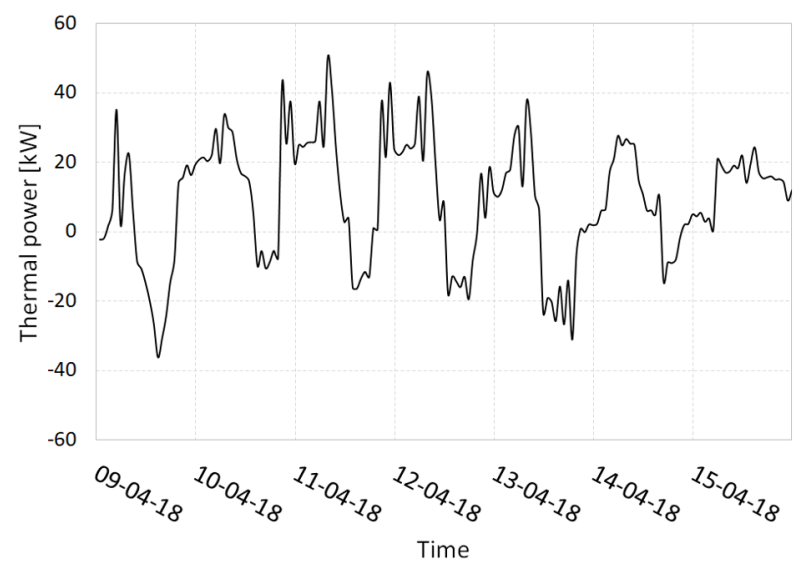

Fig. 11. Thermal power profile during spring week

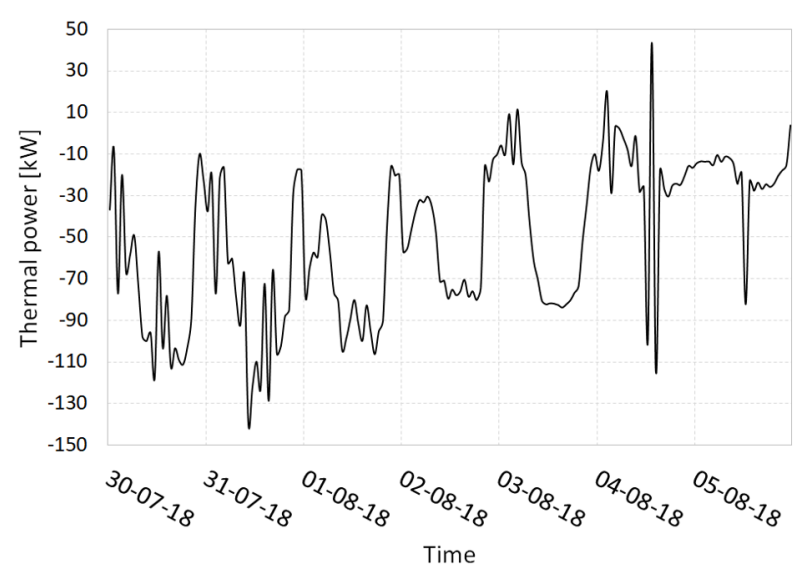

Fig. 12. Thermal power profile during summer week

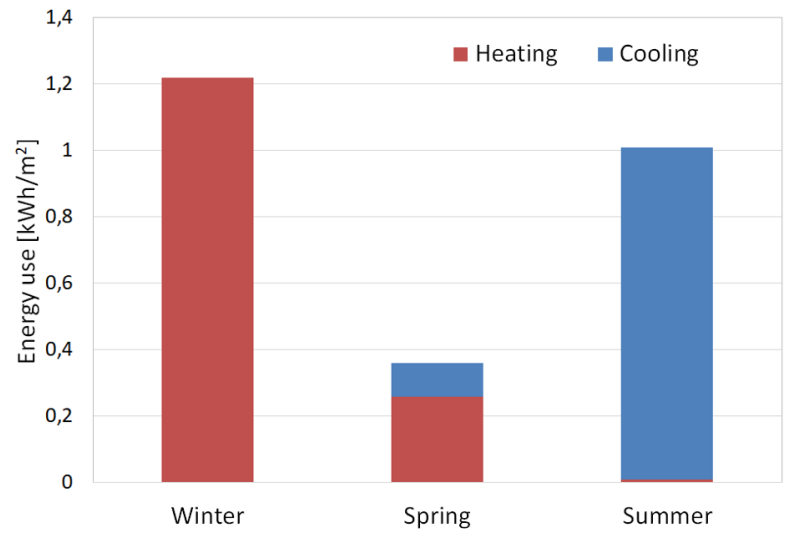

Fig. 13. Energy use of the three typical weeks

\subsection{Indoor air temperatures}

In order to provide an indication of the thermal conditions provided by the two-pipe system, Fig. 14 and 15 shows the daily indoor air temperatures obtained in correspondence of the two locations highlighted in Fig. 6. In winter, the indoor air temperature is between $21.2^{\circ} \mathrm{C}$ and $23^{\circ} \mathrm{C}$, while in summer the indoor air temperature is between $21^{\circ} \mathrm{C}$ and $23.2^{\circ} \mathrm{C}$.

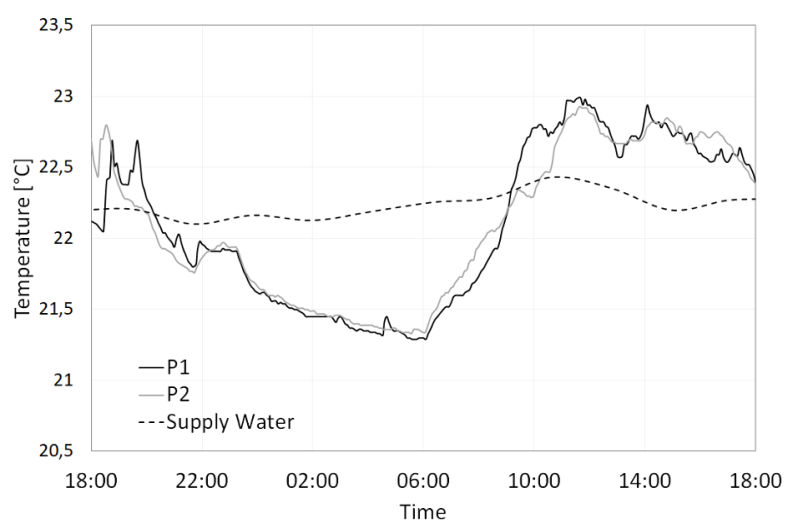

Fig. 13. Air temperature profiles for the winter day

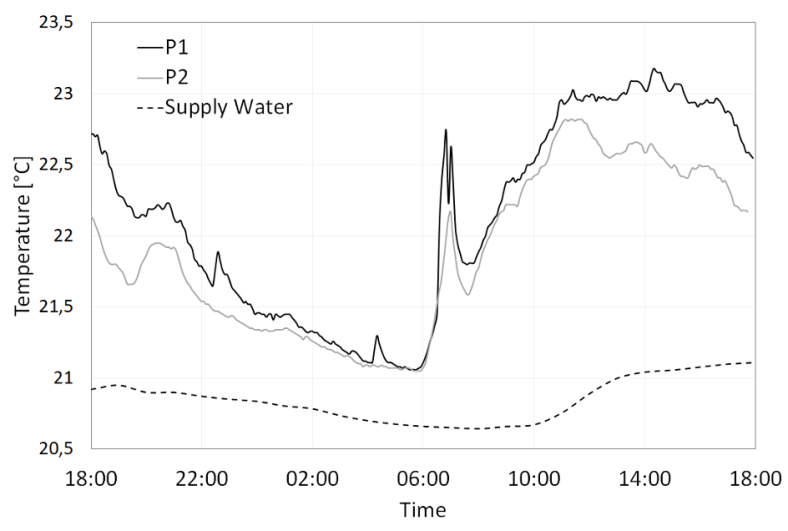

Fig. 14. Air temperature profiles for the summer day 
In winter, there is little difference when comparing the air temperatures in the two locations. In summer, the air temperature closer to the window (P1) is higher than at the inner location. This might be attributed to the influence of solar gains.

Note that the low air temperatures observed in summer during non-working hours are due to the continuous operation of the system. At night, water at about $20.5^{\circ} \mathrm{C}$ circulates in the system, providing cooling energy to the building.

\section{Conclusions}

This paper presents preliminary results regarding an on-going monitoring campaign conducted to analyse the performance of a novel two-pipe active beam system. The novelty of the system is related to the water circuit, which operates supply temperature of approximately $22^{\circ} \mathrm{C}$ all year round. The analysis focused on three typical weeks: winter, spring and summer. Results are provided in terms of supply and return water temperatures, thermal power and energy use. Results from measurements of indoor air temperatures in the building are also shown in order to give an indication of the thermal conditions provided by the novel two-pipe system.

Generally, it can be concluded that the water system operates as designed. The supply water temperature was in the range of $23.2^{\circ} \mathrm{C}$ (winter) to $20^{\circ} \mathrm{C}$ (summer). The highest values of supply/return water temperature differences were observed in winter and summer, and they assumed a value of, respectively, $1.2 \mathrm{~K}$ and $1.5 \mathrm{~K}$. Measurements of indoor air temperature in the building showed that the system is able to provide good thermal conditions in the building. Indoor air temperatures were between $21^{\circ} \mathrm{C}$ and $23.2^{\circ} \mathrm{C}$. Therefore, it can be concluded that the actual operation of the system well matches the predicted operation, as calculated in the design and sizing phase.

The monitoring campaign is still ongoing and it will include analysis of yearly data, DOAS operation and electricity use of pumps and fans. In addition, further studies will investigate the overall perceived thermal comfort in the building by means of questionnaires.

The project has been financially supported by ELFORSK, a research and development program administrated by Danish Energy

\section{References}

1. K. Roth, J. Dieckmann, R. Zogg, J. Brodrick. ASHRAE J. 49, 7-9 (2007)

2. J. Murphy, J. Harshaw. TRANE Eng. 38, 1-12 (2009)

3. J. Wollett, J. Rimmer. ASHRAE (2014)

4. P. Filipsson, A. Trüschel, J. Gräslund, J.O. Dalenbäck. Energy Build. 129 445-451 (2016)
5. A. Maccarini, G. Hultmark, A. Vorre, A. Afshari, N.C. Bergsøe. Build Simul. 8, 543-550 (2015)

6. M. Virta, D. Butler, J. Gräslund, J. Hogeling, E.L. Kristiansen, M. Reinikainen, G. Svensson. REHVA (2004)

7. A. Maccarini, A. Afshari, G. Hultmark, N.C. Bergsøe, A. Vorre. Proceedings of CLIMA 2016 conference (2016).

8. A. Maccarini, G. Hultmark, A. Afshari, N.C. Bergsøe, A. Vorre. Build Simul. 10, 697-710 (2017)

9. A. Maccarini, M. Wetter, G. Hultmark, A. Afhsari, N.C. Bergsøe, A. Vorre. Energy Build. 134. 234-247 (2017)

10. Lindab A/S. SOLUS beam (2016) 